\title{
O QUE REVELAM OS RESULTADOS DE AVALIAÇÕES EXTERNAS SOBRE O ENSINO DA LITERATURA NA FORMAÇÃO DOCENTE?*
}

\author{
WHAT DO EXTERNAL EVALUATION RESULTS REVEAL ABOUT \\ LITERATURE TEACHING IN TEACHER TRAINING?*
}

Juliana A. B. MENEZES**

\begin{abstract}
Resumo: Este artigo apresenta a análise de duas práticas de ensino da literatura que obtiveram bons desempenhos em avaliações externas como o Exame Nacional do Ensino Médio (ENEM). Elas foram realizadas no âmbito do ensino médio de uma escola pública e outra privada, no Estado do Paraná. A análise mostra que bons resultados não necessariamente revelam boas práticas do ensino da literatura, entendendo-se por uma boa prática aquela que se apresenta como relevante na formação de leitores anárquicos, isto é, daquele leitor que consegue ler a partir das contradições inerentes ao mundo e ao homem. Uma vez que o ensino de literatura no ensino médio frequentemente é questionado sob a acusação de que os jovens não gostam de ler os livros solicitados por seus professores, chamaram-nos a atenção os resultados apresentados pelas escolas que foram investigadas, pois, nelas, os alunos conseguem ótimo desempenho nas provas do ENEM. O funcionamento de tais práticas de literatura; a formação dos professores; o perfil docente; o perfil dos alunos; a relação destes com a leitura, com o ensino de literatura e com a prática de literatura foram categorias mobilizadas para chegarmos a tal resultado. Partilhar práticas pedagógicas que conseguem mediar a leitura literária pode contribuir para que se estabeleça sentido no ensino da literatura na escola, especialmente para formar leitores anárquicos. Tais práticas favorecem, para alunos e professores, o encontro de momentos de sensibilização, configurando-se um espaço de aconchego, acolhimento e humanização em um mundo caótico, vazio e cada vez mais veloz.
\end{abstract}

Palavras-chave: Ensino de Literatura. Formação Do Leitor. Avaliação De Literatura. ENEM.

Abstract: This paper presents the analysis of two practices of assessing literature that has achieved good performance in external evaluations. They were carried out at a public and a private high schools in the State of Paraná, Brazil. Results show that good outcomes do not necessarily mean good practices in literature teaching if these are understood as the ones that are meaningful in the formation of anarchic readers, i.e., the reader who can read from the inherent contradictions of the world and of man. Excellent performance at the National High School Exam (ENEM) was surprising, because teaching literature in high schools has constantly been challenged as young people are often considered not to like to read books assigned by their teachers. The survey included categories such as the operationalization of literary practices, teachers' academic education, teachers' and students' profiles, as well as their relationships with reading and with literature teaching and practice. Sharing pedagogical practices that mediate literary reading can help to establish meaning in literature teaching, specially to form anarchic readers. Such practices allow students and teachers to encounter

\footnotetext{
* O artigo aborda recorte dos resultados da tese de minha autoria, intitulada Educação literária no Ensino Médio: estudo de caso das escolas paranaenses, defendida em 2019 no Programa de Pós-Graduação em Letras da Universidade Estadual Paulista Júlio de Mesquita Filho (UNESP).

** Professora da Rede Estadual de Ensino (Paraná). Doutorado em Letras Universidade Estadual Paulista Júlio de Mesquita Filho (UNESP). E-mail: julianaalvesbarbosamenezes@gmail.com.
} 
some awareness moments, making them meaningful as well as comfort and humanizing spaces in a chaotic, empty and fast world.

Keywords: Literature teaching. Reader Formation. Literature Evaluation. ENEM.

\section{Introdução}

Pretendemos discutir aqui algumas questões que consideramos pertinentes para tratar do ensino da literatura nos dias de hoje. Como foco, pensamos o ensino da literatura a partir dos seus resultados. Sabemos que em um mundo movido por resultados, muitas famílias escolhem o espaço escolar em que seus filhos estudarão, observando como os alunos de tais escolas se saem em provas externas, como no ENEM, especificamente, no caso do ensino médio. Desse modo, observar e analisar o contexto de tais espaços, bem como a literatura é ensinada lá, foi, para nós, motivação. Compreender como os docentes de tais escolas, consideradas "sucesso" em desempenho escolar, ensinam a literatura, o que realizam em sala de aula e como realizam suas práticas, fez com que compreendêssemos, também, qual a formação desses sujeitos que atuam como professores de literatura no ensino médio: o que leram, quem os influenciou, o que compreendem por literatura, como realizam suas escolhas de textos para levar aos alunos, como avaliam seus alunos e se, de fato, em tais escolas, os discentes são formados leitores do literário ou saem como técnicos para lerem provas e acertarem o gabarito.

A metodologia utilizada se deu em dois níveis: um quantitativo, que buscou compreender como os professores de literatura, no ensino médio, construíram suas histórias de leitura, realizaram as escolhas dos livros, além da identificação de suas práticas de leitura. Optamos por questionários que foram aplicados pessoalmente na escola para os docentes e discentes. Justifica-se "a ida à escola" pelo fato de que o contato com os envolvidos foi fundamental para perceber o contexto escolar. Já no segundo nível, o qualitativo, optamos por uma entrevista estruturada com os mediadores e alunos sobre suas práticas e suas histórias de leitura. A coleta dos dados aconteceu no primeiro semestre de 2016 e resultou na articulação de questionários com perguntas abertas e fechadas respondidas por dois professores e por um total de 200 alunos. Já a entrevista estruturada com os professores durou aproximadamente cinco horas. Quanto ao número de aulas observadas de cada docente, assistimos a duas aulas, o que é reconhecidamente pouco para estabelecer verificação, portanto, leva-nos a afirmar a importância de triangular os dados: questionários (aluno e professor), entrevista com professores, observação direta das 
aulas e contexto escolar e da aula, para, então, traçarmos de que modo os professores das escolas investigadas realizam suas práticas de literatura e se, de fato, elas são boas práticas.

O questionário aplicado aos professores foi pensado de modo que contemplasse os dados pessoais e os dados sobre seu trabalho. Perguntas como idade, sexo, série em que leciona e nível socioeconômico da escola em que leciona compuseram a primeira parte do questionário, no total, com 08 perguntas. Uma segunda parte, com 53 perguntas no total, foi organizada da seguinte maneira: formação do professor (09 perguntas), práticas culturais (01 pergunta), hábitos de leitura (11 perguntas), representação da leitura (04 perguntas), história do leitor (03 perguntas), professor de literatura (08 perguntas) e ensino de literatura (17 perguntas).

Quatro categorias de análise foram criadas na elaboração das questões. Na primeira categoria, Perfil Docente, antes de compreendermos como a aula do professor se configura, buscamos compreender quem é esse sujeito que atua como docente; sendo assim, como ele se formou, quais práticas culturais ele realiza, quais hábitos de leitura ele possui. Algumas dessas foram perguntas que nortearam nossa tentativa de traçar um perfil do professor. Quanto à segunda categoria, Professor de Literatura: sua história de leitura, partimos do pressuposto de que o professor de literatura, antes de tudo, é um leitor. Desse modo, como esse docente se tornou leitor e como é a sua relação com o objeto de seu trabalho, ou seja, os livros e a leitura, são questões que direcionaram nosso olhar. Com a terceira categoria, Ensino de Literatura: objetivo e concepção, objetivamos compreender de que modo o docente percebe a disciplina, isto é, o que compreende por literatura, qual a sua função e como ele ensina seu aluno a ser leitor. Finalmente, na quarta categoria, Aula de Literatura: metodologia, analisamos quais estratégias o docente utiliza para selecionar textos e obras literárias, levando em conta o perfil adolescente, ou melhor, o repertório desse tipo de público.

A partir das quatro categorias, nosso foco foi identificar quais fatores impactam a prática do professor de Literatura, compreender quem é esse sujeito, como ele se formou, qual o seu nível cultural, quais escolhas ele realiza enquanto leitor, como se tornou professor de literatura, como ele se relaciona com a sua disciplina, ou seja, o docente tem clara uma concepção de seu objeto de estudo, sabe para que serve, além de apresentar conscientemente um método para ensinar tal matéria; somado a esses fatores, como esse sujeito-professor construiu seus saberes e de que modo ele os utiliza em suas práticas, já que o repertório do aluno, nesse nível escolar, na maioria das vezes, não é o repertório exigido pelas obras clássicas que são solicitadas em alguns concursos vestibulares de nosso país e, portanto, guiam e "engessam" esse nível de ensino, conforme afirmou Cereja (2005). As 53 perguntas, às vezes, repetem-se 
propositalmente, pois as respostas dadas como certas pelos docentes são revistas ou melhor detalhadas com outras perguntas. Desse modo, as idas e vindas e algumas repetições foram necessárias.

O questionário elaborado para os alunos (tanto da escola pública quanto da escola privada) foi composto por 47 perguntas, organizados em 6 itens: a) Dados pessoais (composto por 7 perguntas); b) Formação (04 perguntas); c) Práticas Culturais (com 1 pergunta); d) Hábitos de leitura (com 19 perguntas); e) Representação da leitura (com 3 perguntas); f) Aula de literatura (13 perguntas). Ao analisar as respostas, pontuamos aspectos altos e baixos da relação aluno e leitura, aluno e ensino de literatura, bem como aluno e professor, mas verificamos também dados novos, desconhecidos, que surgiram por meio das respostas dos alunos. Desse modo, utilizamos três critérios na escolha das respostas encontradas: 1) Respostas que sinalizaram problemas; 2) Respostas que apontaram curiosidades; 3) Respostas que apresentaram apreciações positivas.

Nossa análise revelou que uma boa prática de literatura não necessariamente é aquela que apresenta os melhores desempenhos, isso porque os alunos, muitas vezes, são apenas treinados para tais modelos de prova. Chegamos a tal resultado, observando diretamente as práticas de uma escola pública, em Curitiba, e outra privada, em Cascavel, ambas no Paraná. Desse modo, trataremos de expor como funcionam essas práticas no contexto que chamaremos de modelo $\mathrm{A}$ e modelo B, a partir do perfil docente, do contexto escolar, do perfil dos alunos e da descrição das práticas lá observadas e analisadas. Em seguida, abordaremos a importância da formação recebida por tais docentes nos cursos de Letras, para, então, tratarmos da importância de aspectos internos do sujeito que será professor de literatura, bem como da importância da formação recebida no ensino superior, por meio do curso de Letras; esses dois fatores juntos serão fundamentais na formação do profissional das Letras, e sua formação contribuirá para uma educação literária que, de fato, forme leitores anárquicos ${ }^{1}$ do texto literário e professores que oportunizem momentos de ruptura com as verdades fortes e impostas no mundo em que vivemos. Assim, uma gestão democrática do espaço escolar dará abertura para sujeitos mais humanizados, solidários com a dor alheia e críticos do mundo em que vivem;

\footnotetext{
${ }^{1}$ Um leitor anárquico é aquele que sabe selecionar, dentre os textos que circulam socialmente, aqueles que podem atender às suas necessidades, conseguindo estabelecer as competências necessárias e adequadas de abordagem de tais textos. Sobretudo, é capaz de ler as entrelinhas, identificando os elementos implícitos, estabelecendo relações interpessoais, e realiza o seu direito ao contraditório, não só com o texto lido, mas, especialmente, com a sua posição social, política, histórica e ideológica. Assim, esse leitor se posiciona sobre o que lê de modo livre e corajoso.
} 
consequentemente, a literatura será ensinada como uma prática social e um ato político.Modelos Escolares

\section{Modelo A - O caso da escola curitibana}

A seguir, nos Quadros 1 e 2, como forma de síntese, são apresentados os dados coletados tanto dos professores, posteriormente (P1 e P2), quanto dos alunos, doravante (A1 e A2).

Quadro 1 - Síntese P1

\section{$1^{\text {a }}$ Categoria: Perfil Docente}

P1 construiu sua formação básica na escola pública e se graduou na PUC-PR, rede privada. P1 está há 19 anos formado e se especializou em Literatura Brasileira e História Nacional, História Brasileira e Inclusão;

P1 valoriza as diferentes práticas culturais, mas, devido aos baixos rendimentos e/ou carga horária elevada, não tem uma vida social diversificada;

P1 considera-se leitor, embora não tenha tido, em seu lar, a influência dos pais na sua formação, uma vez que eles não liam;

P1 não gosta de ler em mídias digitais, pois possui uma relação de afeto com cada livro que leu ou lê.

\section{$2^{\text {a }}$ Categoria: Professor de Literatura}

P1 não vê a leitura como a única fonte de informação e criticidade, embora, para ele, seja a principal;

P1 diz ler para estar em outros mundos e afirma que deixou de ler por obrigação;

P1 considera $o$ ato de ler uma viagem;

P1 acredita que, para formar leitores, é necessário: dialogar, relacionar e estabelecer curiosidades nos jovens.

\section{$3^{\text {a }}$ Categoria: Ensino de Literatura, Objetivo e Concepção}

P1 compreende o ensino de literatura, no ensino médio, a partir de um olhar que estabelece relações da literatura com outros saberes, tais como História, Psicologia e Sociologia, para despertar a criticidade do aluno;

P1 apontou como um dos principais problemas na formação de leitores o grau de esforço e a impaciência do adolescente;

P1 afirma que os livros contemporâneos são os escolhidos pelos jovens, pois são mais fáceis de compreender. Além disso, afirmou também que os meninos realizam escolhas diferentes das meninas, isto é, eles preferem livros de aventura ou mitologia, enquanto elas, romances.

\section{$4^{a}$ Categoria: Prática de literatura}

P1 organiza sua aula a partir de duas fases. 
$1^{\mathrm{a}}$ fase: momento em que escolhe o autor e o período literário que será trabalhado;

$2^{a}$ fase: momento em que realiza a análise da obra e do enredo, da parte gráfica do livro, da linguagem e do vocabulário, bem como o momento em que separa, por capítulos, obras maiores, e busca outros textos que se relacionem com o livro estudado. Por fim, momento de debater com os alunos sobre suas impressões de leitura;

P1 utiliza H.Q. e TV para estabelecer relações com a literatura em sala de aula. Além de teatro, cinema e fotografia;

P1 afirmou trabalhar com as obras exigidas pelos vestibulares da seguinte forma: ensina a teoria e a biografia dos autores, além de indicar leituras para serem feitas em casa;

P1 possui um método de abordagem da literatura em que se apropria de outros suportes e faz o aluno trabalhar em sala de aula, não apenas ser informado sobre os dados dos livros e autores estudados, sendo assim, os alunos se tornam parte do processo;

P1 afirma que forma leitores críticos de literatura, especialmente, com o retorno positivo que recebe de seus alunos e ex-alunos.

Fonte: Elaboração Própria.

Quadro 2 - Síntese de A1

\section{Categoria 1: Perfil do aluno}

A1 representa um total de 89 alunos na faixa de 16 a 18 anos. Mais da metade deles possui a idade certa na série certa. Além disso, existe o dobro de mulheres nas turmas, e a maioria dos alunos são filhos de pais com ensino superior. Constatamos, também, que a turma pertence ao nível socioeconômico médio ou alto;

A1 escolheu as seguintes práticas culturais: $95 \%$ internet, $80 \%$ música e 55\% livros. Desse modo, observamos que a leitura escolarizada não é a primeira opção cultural desses alunos, pois concorre e perde para outras práticas;

A1 afirmou que reconhece a importância da leitura (97\%). Pouco mais da metade deles se considera leitor (57\%) e $80 \%$ afirmou que sabe reconhecer o que é um bom leitor;

A1 quanto às escolhas de leitura: esses jovens buscam ler para se divertir ou evadir os sentimentos.

\section{Categoria 2: Aluno, Leitura, Ensino e Aula de Literatura}

A1 ora compreende a literatura como aquisição da cultura, ora como útil para passar no vestibular. Constatamos uma visão utilitarista da literatura;

A1 quanto ao gosto: todos afirmam gostar, porém, quando sinalizaram os tipos de livros que mais possuem em seus lares, disseram ter livros religiosos, jornais, livros didáticos, revistas, livros autobiográficos e, por fim, romances e contos; 
A1 quanto ao local escolhido para ler: a casa é o lugar escolhido pela maioria; na escola, só leem se o professor pedir. Sendo assim, a escola, que deveria ser um espaço contínuo de leituras, não é, e se o professor não solicitar leituras, verificamos que lá, no espaço escolar, o aluno não lerá;

A1 afirmou, na maioria, que os best-sellers estão entre os livros nunca esquecidos, mas, dentre os poucos clássicos citados, acreditamos que isso tenha ocorrido em virtude das escolhas que professores que tiveram ao longo das suas histórias de leitores;

A1 afirmou também gostar muito de blogues, consequentemente, sinaliza para a importância de relacionar a literatura com outros suportes;

A1 apresentou como critérios de julgamento para apreciar a literatura escolarizada o tamanho da obra, o tema e o enredo;

A1 ao não citar os romances ou obras maiores, salienta a necessidade de um trabalho diferente com essas obras na escola;

A1 respondeu que gosta de escrever, pois eles podem expressar os seus sentimentos. Porém, só escrevem se alguém for ler. Percebemos, desse modo, que a escrita pode ser forte aliada dos professores para incentivar esses jovens "preguiçosos" a ler, a escrever e a trabalhar;

A1 não relacionou a escrita com a literatura. Ao que tudo indica, a segmentação da aula de língua portuguesa em análise linguística, produção de textos e literatura fatia a língua portuguesa em compartimentos, o que parece gerar desencontros: como se ao estudar o jogo das palavras, o ritmo fosse conteúdo de análises poéticas, mas não se apropriam disso quando escrevem seus próprios textos;

A1 afirmou não apreciar a literatura escolar em virtude de: linguagem distante do seu tempo, o uso de vocabulário rebuscado, o enredo é longo demais e se torna muito cansativo, pois o excesso das descrições e dos detalhes são chatos;

A1 prefere enredos com ações, mistérios e personagens mais dinâmicos;

A1 sinaliza para um descompasso entre suas escolhas e as escolhas escolares;

A1 representa universo de leitores, mas não como foram as gerações de nossos pais ou avós, afinal, as práticas culturais e sociais sofreram alterações com o decorrer do tempo. Os jovens leem em outros suportes, tais como: internet, cinema, música, HQ etc;

A1 evidencia que, para o ensino de literatura na escola funcionar, é necessário estabelecer pontes entre as leituras reais e a cultura legitimada;

A1 identificou especificidades da linguagem literária, quando questionados se observavam a linguagem dos autores. Desse modo, constatamos que A1 representa leitores com certo grau de especificidade;

A1 diferencia a história que lê da história contada pelo narrador;

A1 não considera importante conhecer a vida do autor para o entendimento da obra;

A1 evidencia que estudar a literatura escolar, apenas em um viés informativo, não é a melhor abordagem para formar o gosto pela leitura; 
A1 diferencia a leitura no papel da leitura digital; embora a internet tenha sido citada como a primeira opção cultural, 38\% dos alunos não gostam de ler nela, pois o papel é mais envolvente, completo, palpável, rápido para ler, apresenta menos erros gramaticais e é menos cansativo. Mas, $62 \%$ lê na tela; A1 respondeu que os pais compram os livros que forem necessários;

A1, quanto à aula do professor, afirmou que o uso de slides, de vídeos, do material didático e o excesso de teoria tornam a mesma maçante. Em contrapartida, as conexões estabelecidas pelo professor, o trabalho extra sala, a dinamicidade, o uso de recursos moderados, os seminários e os debates estimulam a aula.

Fonte: Elaboração Própria.

Embora não exista nada de mágico na prática de P1, pois realiza um trabalho pautado em escolhas de leituras que são preparatórias para avaliações externas, ele oferece ao aluno momentos para que este trabalhe e participe da construção dos debates durante a aula, ou seja, a prática é ativa. Dessa forma, P1 realiza uma "boa prática", mas o desempenho apresentado por tais alunos em avaliações externas ocorre também porque são estimulados para tais modelos de avaliação. Toda a escola é preocupada em informar datas de provas do ENEM e sites de pesquisa através de cartazes no pátio escolar, por exemplo. Dentro desse quadro analítico, constatamos que uma boa prática é oferecer espaço para o aluno pensar, falar e participar do processo da formação dos sentidos dos textos oferecidos para leitura.

Modelo B - O caso da escola cascavelense

Quadro 3 - Síntese P2

\section{$1^{\text {a }}$ Categoria: Perfil docente}

P2 teve sua formação básica na rede privada de ensino. Primeiro, graduou-se em Direito há 13 anos. Depois, cursou Letras há nove anos, na PUC-PR. P2 possui mestrado em Literatura Comparada; $\mathrm{P} 2$ valoriza as diferentes práticas culturais e tem acesso a uma vida social diversificada; P2 se considera leitor, embora os pais não tenham sido modelo de leitores. Às vezes, o pai lia crônicas, e o irmão foi apontado como a principal figura familiar, responsável pela formação do gosto pelos livros; P2 disse apreciar leituras digitais, especialmente, no Kindle, da Amazon.

\section{$2^{\text {a }}$ Categoria: Professor de Literatura}

P2 compreende a leitura como um ato de transformação e emancipação; 
P2 se diz leitor, mas não um "bom leitor", pois, segundo ele, os docentes, os escritores e os jornalistas conhecidos é quem são exímios e sagazes leitores;

\section{$3^{\text {a }}$ Categoria: Ensino de literatura, Objetivo e Concepção.}

P2 compreende o ensino de literatura, no ensino médio, como a capacidade de prover meios de resolver questões de vestibulares, prepará-los para as exigências do ensino superior e fornecer um vislumbre crítico e analítico do pensamento humano;

P2 realiza suas escolhas de textos a partir do ENEM e das listas dos vestibulares. Segundo o docente, a forma como a literatura é exigida nesses concursos, através dos seus modelos de avaliação, não seleciona leitores críticos de literatura;

P2 sabe que o objetivo de ensinar literatura é formar leitores críticos, porém, os pais que investem na educação de seus filhos esperam que os mesmos passem nos concursos. Logo, ensinar literatura, no ensino médio, das redes privadas é: prover aos alunos meios de resolver questões;

P2 afirmou não formar leitores críticos de literatura, mas sim, um leitor capaz de conhecer e identificar as idiossincrasias técnico-temáticas dos textos escritos, ou seja, o leitor é um técnico;

P2 acredita que a leitura e a resolução de exercícios são as principais alternativas para o trabalho com a literatura, no nível médio;

P2 analisa que os principais problemas apontados na formação do leitor, nesse período, é a cobrança de obras descontextualizadas do repertório desses jovens e a obrigação de transmitir um excesso de teoria. Consequentemente, existe um desprestígio dos alunos, professores e coordenação da "tecnocracia", dentro e fora da sala de aula; a indisciplina e a falta de interesse tornam-se institucionalizadas. Existe um número cada vez menor de alunos que gostam mesmo de literatura;

P2 acredita que o estilo literário, o tema da obra e a abordagem do professor são os responsáveis pela formação de leitores;

P2 afirmou que os jovens preferem os best-sellers, as séries adolescentes, os livros policialescos e poucos clássicos. Os jovens gostam mais de contos em detrimento aos romances e realizam suas escolhas pelo tamanho da obra e pelo tema.

\section{Categoria: A aula do professor}

P2 disse utilizar 4 passos em sua abordagem didática:

Passo 1: analisa e desmonta a obra em blocos estruturais, segundo os elementos da narrativa;

Passo 2: leitura de trechos ilustrativos;

Passo 3: discute o enredo;

Passo 4: debate as possibilidades interpretativas.

P2 utiliza outros suportes relacionados com o texto literário estudado, por exemplo: HQ, músicas, filmes, TV e teatro;

P2 afirmou instrumentalizar os alunos para os vestibulares;

P2 analisa não haver a formação de leitores, mas sim, leitores técnicos da literatura. 
Fonte: Elaboração Própria.

Quadro 4 - Síntese A2

\section{Categoria 1: Perfil do aluno}

A2 totalizam 15 alunos, com faixa etária 14 até 17 anos. As diferenças de idade ocorreram, pois temos uma amostragem de todo o ensino médio (alunos do primeiro, segundo e terceiro anos). Assim como A1, mais da metade são mulheres e filhos de pais pós-graduados. A2 representa um universo de nível socioeconômico médio e alto;

$\mathrm{A} 2$ quanto às práticas culturais, assim como A1: a internet e a música aparecem como a primeira opção cultural; já a leitura, em terceiro lugar;

A2 no que diz respeito à importância da leitura, ao fato de eles serem leitores e se eles reconhecem um bom leitor, todos responderam que sim. Já na definição de bons leitores, não tem abordagem voltada à quantidade de obras, mas sim, à qualidade empenhada na reflexão dos mesmos;

A2, assim como A1, preferem best-sellers;

\section{Categoria 2: Aluno, Leitura, Ensino e Aula de Literatura}

A2, como A1, apresentam visão utilitarista da literatura;

A2 quanto ao gosto: todos disseram gostar e citaram os contos como os gêneros que eles mais possuem em suas casas. Ao contrário de A1, que dizia gostar, mas tem mais livros religiosos. A escolha de A2 sinaliza para enredos curtos, logo, a preguiça e/ou a falta de tempo aparecem como critérios de escolha de uma obra;

A2 quanto ao local escolhido para ler: a casa é o lugar escolhido, especificamente, o quarto, assim como A1;

A2 apresentaram como razões de apreciação ou não da literatura escolarizada o fato de estar baseado no critério de aptidão por áreas, diferentemente de A1;

A2, como A1, gostam de escrever. Além disso, reconhecem a figura do professor como um dos responsáveis em auxiliar a ampliação do pensamento e a escrita como fatores determinantes para formar o gosto pela literatura. Porém, assim como A1, eles não relacionam a literatura com a escrita;

A2 justificou que: a linguagem distante do tempo, o enredo longo demais e o excesso de descrições tornam as obras solicitadas pela escola cansativas;

A2 afirmaram ser leitores, mas também leem outros suportes, conforme disse A1;

A2 também apontaram especificidades e refinamentos na linguagem e diferenças entre a história da história narrada;

A2, diferentemente de A1, consideram importante saber sobre a biografia do autor para compreender o livro lido; 
A1 e A2 consideram esvaziar o sentido do texto, uma abordagem didática meramente historiográfica; A2, ao contrário de A1: mais da metade deles não gostam de ler na tela, enquanto $47 \%$ gosta de ler. Os motivos foram os mesmos apontados em A1;

A2 também não possui problemas na aquisição de livros, pois os pais compram para eles;

A2 quanto à aula, do mesmo modo que $\mathrm{A} 1$, sabe diferenciar aspectos maçantes e estimulantes. Os alunos identificaram como fatores maçantes de uma aula: aula só teórica, aula de um único romance, quando a linguagem do livro é muito complicada. Já os aspectos estimulantes citados foram: a atualização da obra feita pelo docente, a explicação do professor, quando o tema interessa e as curiosidades da vida do autor.

Fonte: Elaboração Própria.

A prática de P2 é bastante historiográfica, e os alunos, no momento da observação das aulas, encontravam-se muito dispersos e desinteressados. Nesse sentido, a reprodução de dados das obras literárias não se revela como uma boa prática de ensino, logo, o aluno termina por decorar dados das obras e se distancia, ainda mais, da leitura escolarizada, modo de leitura que os alunos, supostamente, deveriam ser capazes de realizar. Conforme dissemos, ainda assim, o bom desempenho desses alunos em avaliações externas ocorre, uma vez que são treinados para tais resultados.

Disso tudo, decorre o fato de que ambas as práticas são tecnicistas e não contribuem para a formação de um leitor anárquico. Atribuímos tal questão a fatores que estão relacionados com as características individuais (história de vida, história de leitura e história da escolha da profissão docente) bem como à formação recebida nos bancos universitários dos cursos de Letras. Esses fatores juntos revelam práticas vazias do ensino de literatura. Consequentemente, tais práticas não contribuem na formação de leitores anárquicos, mas terminam por afastar ainda mais os alunos da leitura do literário, pois eles repetem informações técnicas extraídas do material didático e decoram elementos da historiografia. Sobre o papel dos cursos de Letras na formação de futuros docentes, trataremos a seguir.

\section{O Papel dos cursos de Letras}

Romper com a crise em que se encontra o ensino de literatura no ensino médio é algo que envolve todos os responsáveis no processo de formação de leitores críticos. A começar pelo papel fundamental que os cursos de Letras exercem na formação de nossos professores, passando por práticas que rompam com a historiografia literária e oportunizem maiores debates e voz aos alunos, com abertura aos outros modos de ler que não apenas as leituras canonizadas. 
Desse modo, torna-se necessário, também, uma concepção clara do objeto da literatura e da leitura, políticas e programas de incentivo à leitura que não se findem a cada mandato, mas que perdurem em uma política de continuidade, em que bons projetos sejam aproveitados e ampliados, ao invés de abandonados. É preciso ainda que as bibliotecas tenham seu real valor e que os professores, sendo eles leitores, escolham leituras que dialoguem e que realizem o percurso entre o gosto do aluno e a ruptura desse gosto, em um movimento dialético da contradição, a ser uma busca constante nas práticas docentes. É o olhar do professor e o modo como esse profissional realiza suas mediações que pode ou não contribuir para práticas eficientes da literatura, a fim de romper com a passividade desse leitor repetidor do literário e contribuirmos, de fato, para a formação de leitores anárquicos. Logo, nem sempre bons resultados em avaliações externas, conforme vimos, dão conta de formar leitores de verdade.

Não podemos ignorar que, a cada dia, a formação do profissional de Letras, notadamente a do professor de Literatura, está presa aos padrões do século XIX, essencialmente marcados pelo olhar positivista, que ignora as inovações estéticas, formação quase sempre fincada nos famigerados estudos de estilos de época, pautados no historicismo estéril, que ignora o caráter artístico da obra literária e que a nada levam, a não ser ao tédio do possível leitor-iniciante. Disso, não significa que ignoramos ou não reconhecemos os avanços nas práticas escolares que devem ser atribuídos à evolução da teoria, mas, se a educação básica redimensionará a sua abordagem com os livros a fim de formar, de verdade, leitores mais humanos, parece que, ao ensino superior, também, terá de redimensionar suas práticas, com o intuito de formar professores que atuarão na rede básica e não serão pesquisadores.

Muitos são os problemas que envolvem o ensino de Literatura nos cursos de Letras: a trajetória da disciplina em si, o perfil do aluno e sua profissionalização, a relação do ensino superior com a educação básica e o vestibular (que, na maioria das vezes, regulamenta o ensino secundário), a imaturidade e a falta de leitura dos alunos que ingressam no curso. Revela-se um contexto de conflitos entre a formação inicial do professor de Literatura, nos cursos de Letras, e a crise do ensino de literatura, no ensino médio, acentuados após a publicação da resolução 492, de 3 de abril de 2001, que determinou a modificação dos currículos e dos projetos pedagógicos das licenciaturas, no que parecia ser uma contribuição para a real função do curso de Letras, ou seja, preparar o aluno para a docência e para a atuação na educação básica.

A metodologia adotada pelos professores era uma breve exposição dos movimentos literários com características e datas, fatos históricos, bem como a biografia de seus autores e os fragmentos de textos. Era marcada pela ausência de debates e discussões, até porque os textos 
nunca eram lidos na íntegra. As aulas eram focadas no saber do professor que, eventualmente, realizava uma interpretação do material didático para os alunos. Ao aluno, não importava ler, não precisava debater. A memorização e as respostas esperadas pelo professor e pelo livro didático eram o papel a ser cumprido pelo aluno.

Os cursos de Letras deveriam possibilitar um amplo debate sobre o ensino de literatura na educação básica. Isso deveria ocorrer não apenas a partir das disciplinas de estágio e prática, mas em um diálogo com as demais disciplinas de literatura, uma vez que todas são essenciais para a formação de formadores de leitores. Acreditamos ser o estágio o responsável por apresentar ao graduando a realidade escolar e por incutir nele o sentimento de que conhecimentos adquiridos ao longo da graduação não são suficientes para o exercício docente, mostrando-lhe a necessidade da constante pesquisa. Todavia, sem o conhecimento teórico das demais disciplinas, a prática docente fica incompleta. Muitas vezes, o professor da educação básica não se coloca como pesquisador, porque foi "domesticado" a imitar nos bancos universitários, logo, para deixar de ser um “ensinador”, teria de repensar atitudes e aprender a ser pesquisador, como afirma Pedro Demo (1994). Além disso, os programas universitários apresentam uma grade com pouca ênfase nas disciplinas que ensinam leitura, ocasionando uma falta de reflexão sobre o tema, por parte dos futuros formadores de leitores.

Desse modo, carece-se de um profissional que conheça profundamente os saberes da formação das disciplinas e do currículo, conforme analisou Tardif (2002), além de reconhecer, em sua experiência, uma fonte de saber para sua prática. Os desafios são imensos e exigem um novo professor que reflita sobre sua própria prática, afinal, é impossível continuar a formar professores apenas discutindo teoria sobre literatura. Sendo assim:

Os futuros professores reproduzem a forma como assimilam a concepção de ensino e as metodologias na universidade. Assim, usam a prática docente baseada em saberes disciplinares. Esses saberes são provenientes das disciplinas específicas oferecidas pela universidade e emergem da tradição cultural e dos grupos sociais produtores de saberes. (TARDIF, 2002, p. 38).

Talvez assim, todos nós, inseridos tanto no ensino superior quanto na educação básica, consigamos desempenhar nosso papel e contribuir para romper, no universo da sala de aula, com a passividade e com a acomodação do jovem leitor, com práticas que considerem a participação do leitor e o contato efetivo com as obras literárias. No entanto, para isso, precisamos do apoio coerente, comprometido e sério das políticas públicas, que valorizem a educação, bem como a leitura no país. Tais escolhas revelam o professor, o aluno e a educação 
que concebemos. O que queremos com a educação e com o ensino da literatura na escola é uma pergunta sempre em construção e que, a nosso ver, necessita ser sempre revisitada por todos.

\section{Considerações Finais}

O que observamos em nossa análise foi fundamental para compreender que bons resultados em modelos externos de avaliação, como o ENEM, não necessariamente revelam boas práticas do ensino de literatura. Compreendemos por boa prática uma prática que seja relevante e que se preocupe com a formação de um leitor anárquico, isto é, aquele que consegue ler a partir das contradições, assim como sinalizou Petrucci (1999).

As análises contribuíram para que a escola básica possa repensar seus objetivos e a relevância da abordagem com a literatura escolarizada, com jovens em contexto digital, e para que os cursos de licenciatura tenham clareza do que pretendem na formação do docente em Letras. É um desafio para todos - professores, pesquisadores, famílias e governo - formarem leitores anárquicos de literatura, que enxerguem o outro nas suas singularidades e alteridades; que, portanto, sejam humanos.

Compreendemos ser a literatura uma alternativa em uma sociedade pós-moderna, pois sua natureza dialética traria o reequilíbrio social (CANDIDO, 1970). Temos de ser contrários ao pensamento confortável do presente, pensando em pequenas intervenções para desestabilizar o sistema, ou seja, nada é o que parece ser, afinal, nem tudo está dito. Só sabemos o que significa alegria, porque conhecemos a tristeza e o amor, por sabermos o que é frustração. Para compreendermos melhor sobre a importância do contraditório, em todas as áreas, o olhar contraditório é um direito humano essencial ao processo democrático, conforme expõe Portanova (2001), o princípio do contraditório é elemento essencial ao processo. Mais do que isto, pode-se dizer que é inerente ao próprio entendimento do que seja processo democrático, pois está implícita a participação do indivíduo na preparação do ato de poder. A importância do contraditório se irradia para todos os termos do processo. Tanto é que conceitos como ação, parte e devido processo legal são integrados pela bilateralidade. Dessa forma, o juiz, antes de decidir (resolver o litígio - no processo civil -, ou acertar o caso penal - no processo penal), deve ouvir ambas as partes (audiaturet altera pars), oportunizando a elas (autor e réu) igualdade de condições, uma vez que o contraditório "refere-se à oportunidade que é dada à parte de contrariar os atos da parte adversa" (FERNANDES, 2005, p. 66). Para eu ver o outro, preciso retroceder e, então, avançar e reconhecer que o olhar do outro pode não ser como o meu. Essa 
dialética é o que torna possível à consciência humana evoluir e, assim, de fato, estabelecermos o diálogo.

Quando a leitura literária é ensinada de modo crítico e tratada como um direito de todos e não apenas de um grupo menor, quando ela não é pretexto de regras de boa conduta ou pedagogismo, tal arte realiza sua função e contribui para o surgimento de uma pessoa melhor, mais consciente do direito do outro, portanto, menos autoritária, violenta e opressora. Dessa maneira, definimos como um leitor anárquico aquele que lê com o olhar libertário das amarras sociais e poderá ser formado, a partir de uma escola democrática que enxergue a leitura literária como uma prática social e um ato político. Vivemos em um mundo externo, porém, temos um mundo que é interno, e, na maioria das vezes, ele é ignorado em detrimento do capital. Por isso, ensinar literatura é um ato provocador e questionador, porque não podemos apenas formar leitores que sejam bons técnicos para passar em exames e trazerem bons resultados, mas também é dever do professor questionar o sistema.

Nesse sentido, conforme Zizec (2010), precisamos ser polifônicos contra as verdades fortes e buscar o diálogo entre a alta e a baixa cultura como um mecanismo para voltarmos a pensar. Desse modo, talvez encontraremos um humanismo possível de defender os grupos sociais e a humanidade dentro da lógica capitalista. Temos de ser contrários ao pensamento confortável do presente, pensando em pequenas intervenções para desestabilizar o sistema, isto é, nada é o que parece ser, afinal, nem tudo está dito. Essa dialética é o que torna possível à consciência humana evoluir e faz o ensino de literatura ser uma educação do olhar a si mesmo e ao outro com maior compaixão e solidariedade. Só assim terá sentido ensinar literatura e formar, de fato, leitores.

Portanto, o resultado das provas no ENEM em tais escolas revelou como esses professores foram formados em casa e nas universidades, bem como o modo como suas práticas foram marcadas por suas histórias. Exemplo disso, quando o professor da escola pública informou que os pais não eram leitores, mas que a escola possibilitou que ele se apaixonasse pelos livros e, para além disso, que onde ele estudou não havia práticas com a leitura literária, mas que o ensino era historiográfico. Porém, conforme vimos, tal professor oportunizou momentos significativos com o texto em sua sala de aula, já como docente, pois oferecia voz ao aluno, logo sua prática era ativa. Já, o professor da rede privada, embora tenha tido exemplos em sua casa de leitores e se dissesse ser alguém acostumado com as novas tecnologias, sua prática historiográfica e a falta de interesse dos alunos durante a aula do docente indicaram que, além da história de leitura e de formação de tal professor, o modo como o literário é abordado em 
sala de aula não era libertário. Isso indica que sua visão "moderna" não se efetua nas suas práticas bastante conservadoras e que pouco contribui para a formação de leitores críticos. Revelam também que nem sempre boas notas são sinônimas de leitores que leiam o mundo para além de suas próprias histórias, sobretudo que estejam dispostos a conhecer a realidades adversas das deles, a divergirem sem se agredirem, a debater e a dialogar sem xingamentos ou ofensas pessoais, afinal, o mundo é todo linguagem, e o que desejamos é que ele seja cada dia mais acolhedor, humano, solidário, amigo e justo para todos nós.

\section{Referências}

CANDIDO, A. A literatura e a formação do homem. Ciência e Cultura, São Paulo, SP, v. 24, n. 9 , p. 803-809, set. 1970.

CEREJA, W.R. O dialogismo como procedimento no ensino de Literatura. In:

Ensino de Literatura: uma proposta dialógica para o trabalho com a literatura. São Paulo: Atual, 2005, p.162-195.

DEMO, P. Pesquisa e construção do conhecimento: metodologia científica no caminho de Habermas. Rio de Janeiro: Tempo Brasileiro, 1994.

FERNANDES, A. S. Processo penal constitucional. 4. ed., Rev., atual. e ampl. São Paulo: RT, 2005.

PETRUCCI, A. Ler por ler: um futuro para a leitura. In: CHARTIER, R\& CAVALLO, G.

História da leitura no mundo Ocidental. São Paulo: Ática, 1999.

PORTANOVA, R. Princípios do processo civil. 4. Ed. Porto Alegre: Livraria do Advogado, 2001.

TARDIF, M. Saberes docentes e formação profissional. Petrópolis: Vozes, 2002.

ZIZEC, S. Como ler Lacan. Rio de Janeiro: Zahar, 2010, 146p.

Recebido em: 11/05/2020

Aceito para publicação em: 18/09/2020 